\title{
LET IN THE WIND: A PASSIVE DESIGN PARADIGM FOR LARGE BUILDINGS IN THE INNER CITY OF SHANGHAI AND SINGAPORE
}

\author{
QIANNING ZHANG \& STEPHEN SIU YU LAU \\ School of Design and Environment, National University of Singapore, Singapore
}

\begin{abstract}
The paper presents a critique on the challenges arising from a prevailing Asian Compact City syndrome featuring a shared mission to build bigger, larger and taller, and discusses plausible remedies. The massiveness and increased building heights in close proximity suffocate the natural ventilation and create urban heat islands, which leads to increased energy demands during the summertime in the Asia mega cities. CITIC Plaza in Shanghai, Westgate and the Education Resource Centre in Singapore are selected as case studies for discussing the potential and possibility of natural ventilation strategy in the urban complex of the inner-city area to archive "green". Compared to the traditional layout with airconditioned atrium, the public space of these selected buildings is naturally ventilated, making the most of the prevailingly seasonal wind. The results of both simulations and field measurements indicate that it is possible and feasible to apply natural ventilation within high-density urban areas. Pedestrianfriendly wind environment can be archived inside the complex by prevailing wind-driven design planning strategy for mega building, which is cost-effective and eco-friendly. The practical experiences of the passive design paradigm for large, big and tall buildings in the inner city could serve as references for other Asian mega cities.
\end{abstract}

Keywords: thermal comfort, natural ventilation, passive design, Urban Heat Island, green building.

\section{INTRODUCTION}

Currently, the compact cities in Asia is an inevitable trend. This overwhelming tendency has caused heated debate. The critiques are on these challenges for a prevailed Asian Compact City syndrome featuring a shared mission to build bigger, larger and taller, and discuss plausible remedies. Within this context, the architects are bounded to pay more attention to figuring out proper and optimized design strategies for these bigger, larger and taller buildings.

\section{LITERATURE REVIEW}

\subsection{Urban Heat Island (UHI) effect and energy demands}

In recent decades, an increasing number of researchers, experts, and the public have been concerned about the phenomenon of urban heat island (UHI) effect. This well-studied phenomenon indicates that the temperature of a compact urban area is higher than that of its surrounding undeveloped space and the difference will increase with urban development [1]. This heat island phenomenon has boosted a significant stress on the thermal environment of developed urban areas. How to deal with this phenomenon during the rapid urbanization in Asia has been a heated topic. Although the reasons causing the significantly higher temperature in developed urban areas are complicated, the UHI effect follows a fundamental rule. This rule is the first law of thermodynamics, stating that within the energy transformation from one form into another, the total energy will remain the same. No energy will be created nor will it disappear. During the urban development, this fundamental law indicates that all the heat produced by human activities, building operation and maintenance 
will be conserved in the inner urban systems and thus the temperature of the inner-city area will increase.

To alleviate the UHI effect, building energy consumption should be reduced, and building performance and efficiency should be improved. Since all actions taken will influence thermal comfort, green technologies are needed to be introduced into the building system to maintain the thermal comfort.

\subsection{Urban Heat Island (UHI) effect in Shanghai and Singapore}

In Shanghai, the research on Urban Heat Island effect started in the 1950s [2]. The Urban Heat Island effect has existed in Shanghai for an extended period, and it tends to be more severe and intensive as time goes by [3]. The relevant research of this effect in Singapore was first conducted by Nieuwolt in 1966. The result showed that the maximum Urban Heat Island effect caused 4.5 C difference at night [4]. Since then, similar findings on Singapore Urban Heat Island effect are pointed out by quite a few studies, such as the study from SMS in 1986, Goh and Chang in 1998, Wong and Yu in 2005, etc. [5].

\subsection{Wider range of comfort zones in naturally ventilated areas}

Indeed, thermal comfort can be $100 \%$ fulfilled in the air-conditioned environment [6]. However, is the air-conditioned environment the best choice for designers and building users? Is it possible that dynamic environment with proper air movement superior to the stable and steady spaces? Human factors are rarely taken into consideration in the former studies. To some extent, the needs of humanity towards nature are ignored in the standards and practice of green buildings. The survey indicated that appropriate wind velocity contributes to enhancing the thermal comfort condition for some outdoor activities [7]. This study implicates that the thermal comfort improvement also exists in the semi-outdoor space with natural or hybrid ventilation systems. Another survey conducted by Wong in 2003 focused on the thermal comfort in classrooms under the tropical climate, and the results pointed out though the objective data indicate the building areas "uncomfortable", the subjective questionnaire shows the thermal conditions are quite acceptable. Students adapt to the dynamic environment, and they are more accustomed to it than the universal regulations expected. Similar outcomes were also noticed in natural-ventilated public houses in Singapore [8]. The residents regard the thermal conditions acceptable when the analyzed data indicates that they should feel too hot and be thermally uncomfortable. Even more than 20 years ago, the research launched by de Dear in 1991 pointed out that both international and local benchmarks of thermal comfort have underestimated the range of comfort zones in naturally ventilated indoor climate. All these previous research studies are implicating that the predictions of thermal comfort models are likely to be too conservative and there are potentials to introduce more passive ventilation strategies into the indoor or semi-open spaces to lower the air-conditioning energy consumption while still keeping the users feeling thermally comfortable.

\section{CLIMATE FEATURES}

\subsection{Climate features of Singapore}

Singapore is located near the Equator and has a typically tropical climate, with abundant rainfall, high and constant temperatures, and high relative humidity all year round. Air 
temperature, relative humidity, and some other climatic variables are consistent and remain quite stable in different months and seasons throughout the year.

The prevailing seasonal winds of Singapore are from north, northeast (N - NNE) and south, southeast (S - SSE), where the monsoon flow dominant the wind sources. In details, the seasonal wind conditions are divided into the Northeast Monsoon Season (from December to early March), the Southwest Monsoon Season(from June to September) and two Inter-Monsoon Period between them (from late March to May, from October to November).

\subsection{Shanghai}

The climatic feature of Shanghai is relatively more complicated than that in Singapore. In the classification system from the China Academy of Building Research, the climate in Shanghai is defined as "hot-summer and cold-winter", where the weather is hot and humid in summer while cold and moist in winter. In this study, summertime and transition seasons (spring and autumn) are involved due to the fact that naturally ventilated strategy to deliver thermal comfort is not applicable for the humid and cold winter in Shanghai.

According to the software WeatherTool, the psychrometric chart indicates that the range of "feeling comfort" field can be enlarged by natural ventilation evidently in Shanghai. The points with different colors in the graph represent different months. Integrating green concept while regenerating the compact urban areas in Shanghai with natural ventilation is possible and effective.

Meanwhile, the chart Comfort Percentages figures out that the improvement of individual comfort percentages caused by passive design strategy of natural ventilation in Shanghai is evident especially during the transition seasons, namely spring and autumn. In the hot and humid summertime, especially July and August, the improvement exists but not as significantly as that in transition seasons. The potential design strategies are proposed to mitigate UHI, including manipulating building layout and mass to improve shading during the day while facilitating site ventilation at night [9]. Natural ventilation in the night-time provides cooler air to help remove heat contained in the building structures, making contributions to energy savings by reducing active cooling in the daytime.

\section{METHODOLOGY}

\subsection{Site selection}

In this study, the architectural spaces are classified into three categories, namely the air-conditioned indoor space, the hybrid space (natural + mechanical ventilation) and semi-outdoor space (natural ventilation). This study is mainly of the latter two kinds of space. Two commercial complexes one educational building with the feature of passive ventilation design in compact urban areas are selected. One commercial building located in Shanghai while the rest two sites selected are in Singapore.

\subsection{Measurements}

TES-1341 Hot-Wire Anemometer is selected as the measuring apparatus in this pilot experiment. 


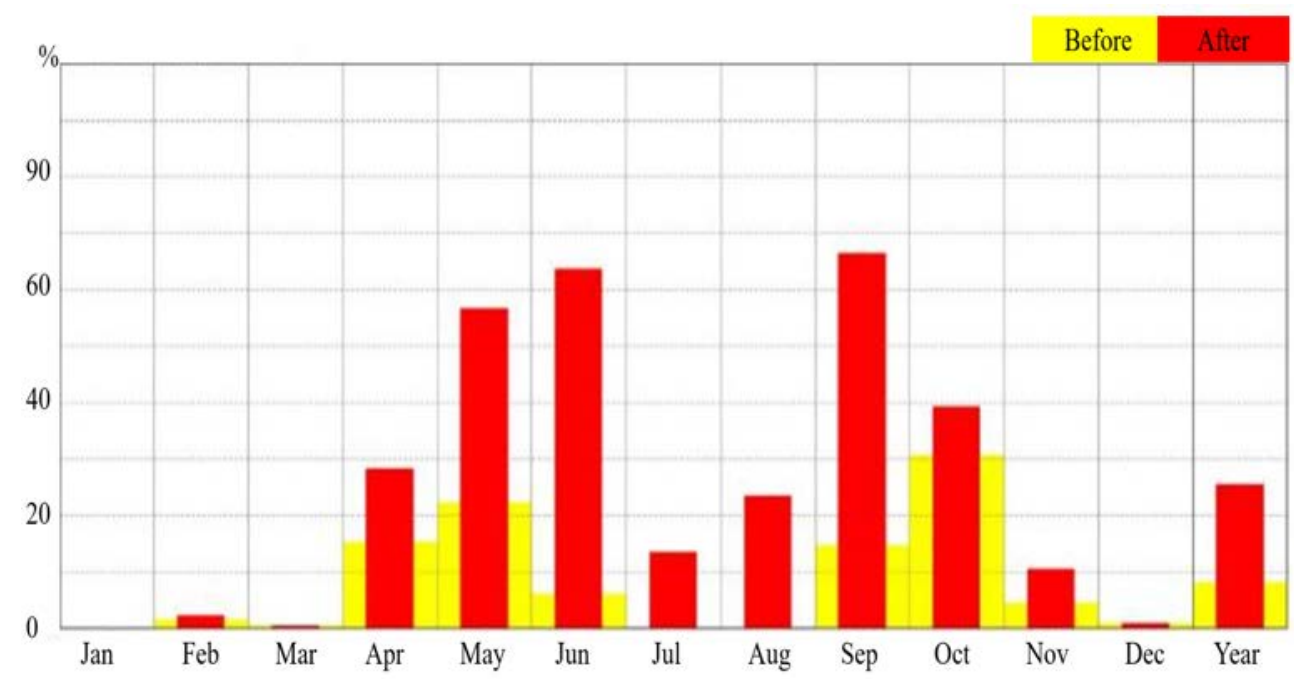

Figure 1: Comfort Percentages enhanced by Passive Design Strategy of Natural Ventilation. (Source: WeatherTool.)

The open spaces of the selected projects are naturally ventilated. All the wind tunnels are measured, and the measured spots are at the beginning, in the middle and at the end of each wind corridor. For the measurement of each wind corridor, the data were recorded at three spots every 10 seconds, lasting $10-15$ minutes.

\subsection{Simulation}

Since all the measurements are conducted in Singapore, and there was no field trip in this semester to Shanghai. The natural ventilation at the Living Style Mall, the podium of the CITIC Plaza, is simulated by the software Airpak to simulate the wind velocity and wind pressure on different floors of the CITIC Plaza.

Natural ventilation is significantly positive during those transition seasons in Shanghai, and prevailing wind direction during these periods are east wind and southeast wind.

A southeasterly wind is the prevailing wind in the summertime of Shanghai, in which the wind frequency of east wind is more than 416 hours at the wind speed of approximately $15-20 \mathrm{~km} / \mathrm{h}$ per year and there is annually more than 250 hours' south wind according to the weather data provided by Energy Plus. The weather data is collected in the district of Hongqiao, Shanghai.

The wind simulation and analysis indicates that the layout of small volumetric blocks in the Living Style Mall is reasonable for natural wind ventilation under the condition of prevailing east and south wind. The wind velocity is enhanced in the gaps of the small blocks. Meanwhile, different wind pressures on building façades lead to the possibility of effective indoor natural wind driven ventilation. 

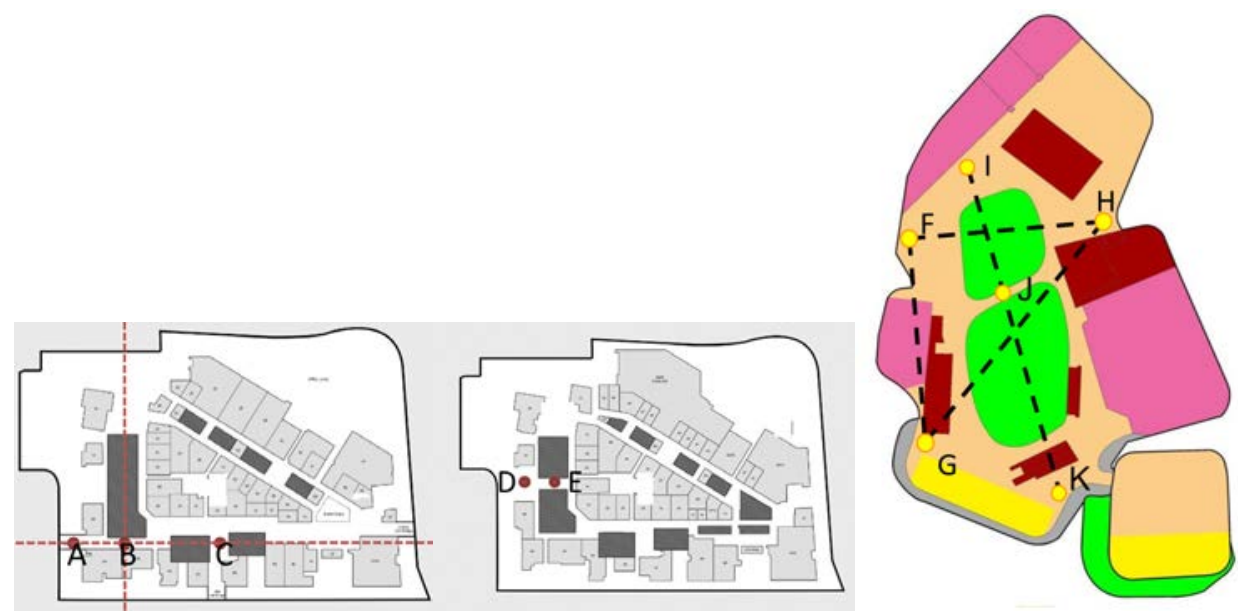

Figure 2: The measuring points in the Westgate (left) and the Education Resource Center (right).

East wind permeability

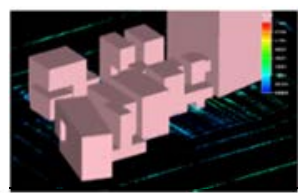

Ventilation stimulation at the building height $+1.2 \mathrm{~m}$

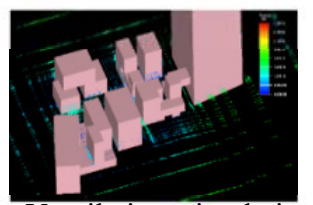

Ventilation stimulation at the building height $+6.2 \mathrm{~m}$
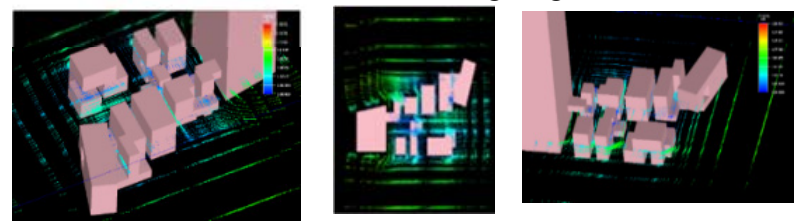

Ventilation stimulation at the building height $+11.2 \mathrm{~m}$
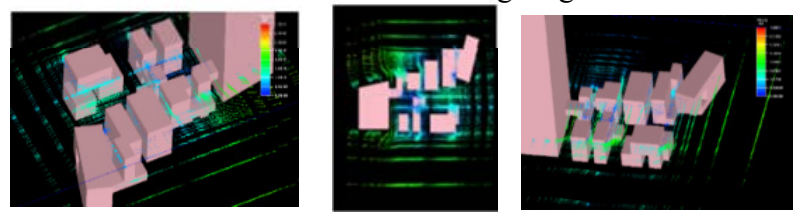

Ventilation stimulation at the building height $+16.2 \mathrm{~m}$
South wind permeability
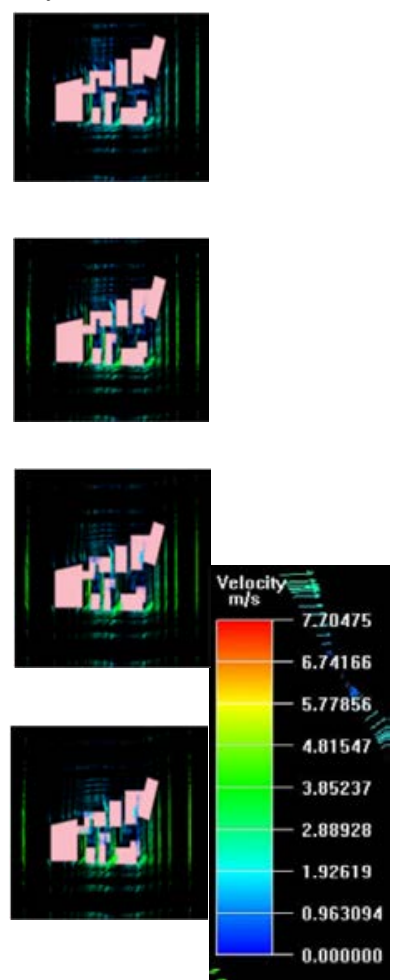

Figure 3: Ventilation simulations at different building heights. 


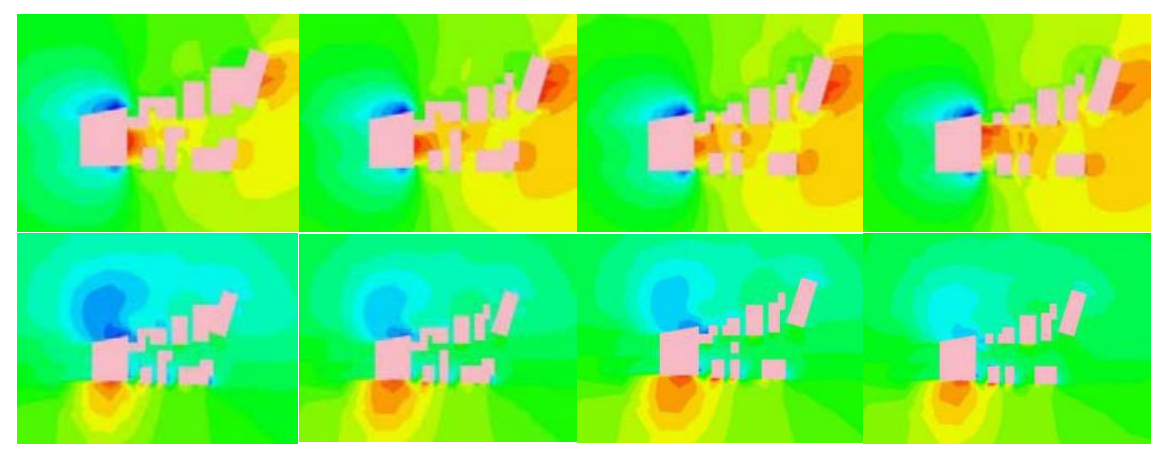

Figure 4: Wind pressure stimulations at different building heights, red areas indicating positive air pressure while blue areas indicating negative air pressure.

\subsection{The preliminary findings}

1. The wind velocity is significantly increased in the junction of wind tunnels. This phenomenon can be observed in the Westgate. For example, in the Fig. 5, the wind velocity is significantly enhanced due to Point B is the junction of two wind tunnels.

2. The wind velocity is strengthened in the gaps of small blocks and wind tunnels. For example, the vertical points $\mathrm{D}$ and $\mathrm{E}$ in Westgate are located near each other. The differences are that Point $\mathrm{E}$ locates in the middle of the atrium and Point $\mathrm{D}$ is located in a narrow corridor surrounded by building blocks on two opposite sites. The results indicate that the wind velocities in Point $\mathrm{D}$ are significantly higher than those in Point E on Level 1 and Level 3 (Fig. 6). Meanwhile, in the simulation of the CITIC Plaza, the result also indicates that the wind velocities are enhanced when the winds go through the narrow gaps between two blocks.

3. The location of wind harvesting ports should be designed to capture the prevailing seasonal wind. The measurements were recorded in August, which was during the Southwest Monsoon Season of Singapore. In the experiment, all five wind harvesting ports are spotted and measured. The results verified the influence of monsoon. Point I and Point $\mathrm{H}$ are located on the north side of the building. The winds in these two points are significantly stronger than the other wind corridors (Fig. 7).

4. Different wind pressures on the building façades lead to the possibility of effective indoor natural wind driven ventilation. The results indicate the small volume of each block improves effective natural wind driven ventilation. The depth of each block becomes small, and it enhances the natural wind driven ventilation. For example, the simulation results of CITIC Plaza show each small block of the project has significant wind pressure difference on opposite façades. Hence, the draughts can flow through the indoor space of each small block to naturally ventilate. 
Wind velocity $(\mathrm{m} / \mathrm{S})$ of Point $\mathrm{A}, \mathrm{B}$ and $\mathrm{C}$

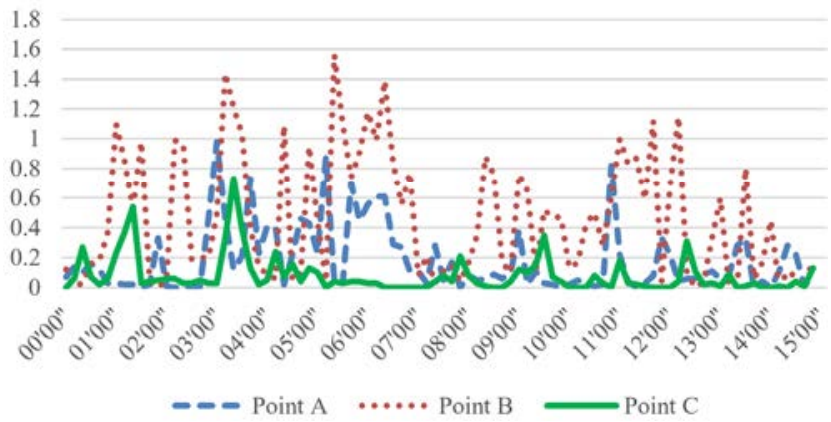

Figure 5: The wind velocity is significantly increased in junctions of wind tunnels. The records of wind speeds from Point B are relatively higher than those from Point A and Point C (Level 2 Westgate).

Wind velocity $(\mathrm{m} / \mathrm{s})$ of Point D1 and E1, Level 1.

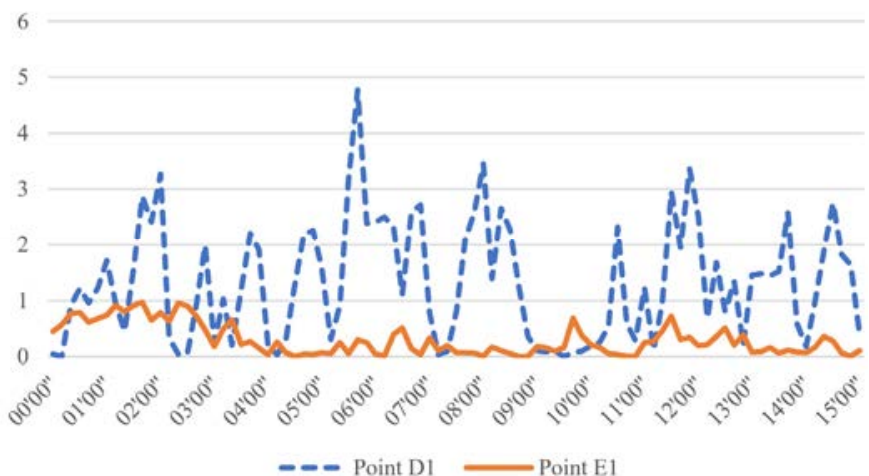

Wind velocity $(\mathrm{m} / \mathrm{s})$ of Point D3 and E3, Level 3.

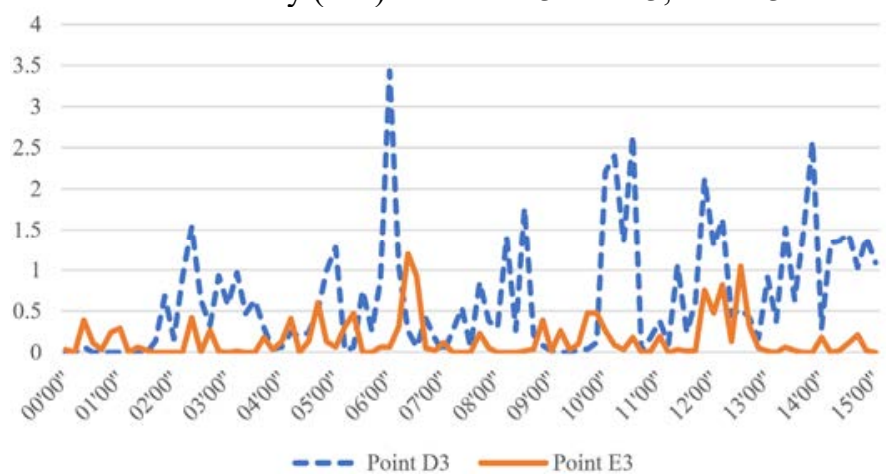

Figure 6: The wind velocity is enhanced in the gaps of small blocks and wind tunnels. Fluctuations of wind speeds and the records of wind speeds from Point D are higher than those from Point E. 


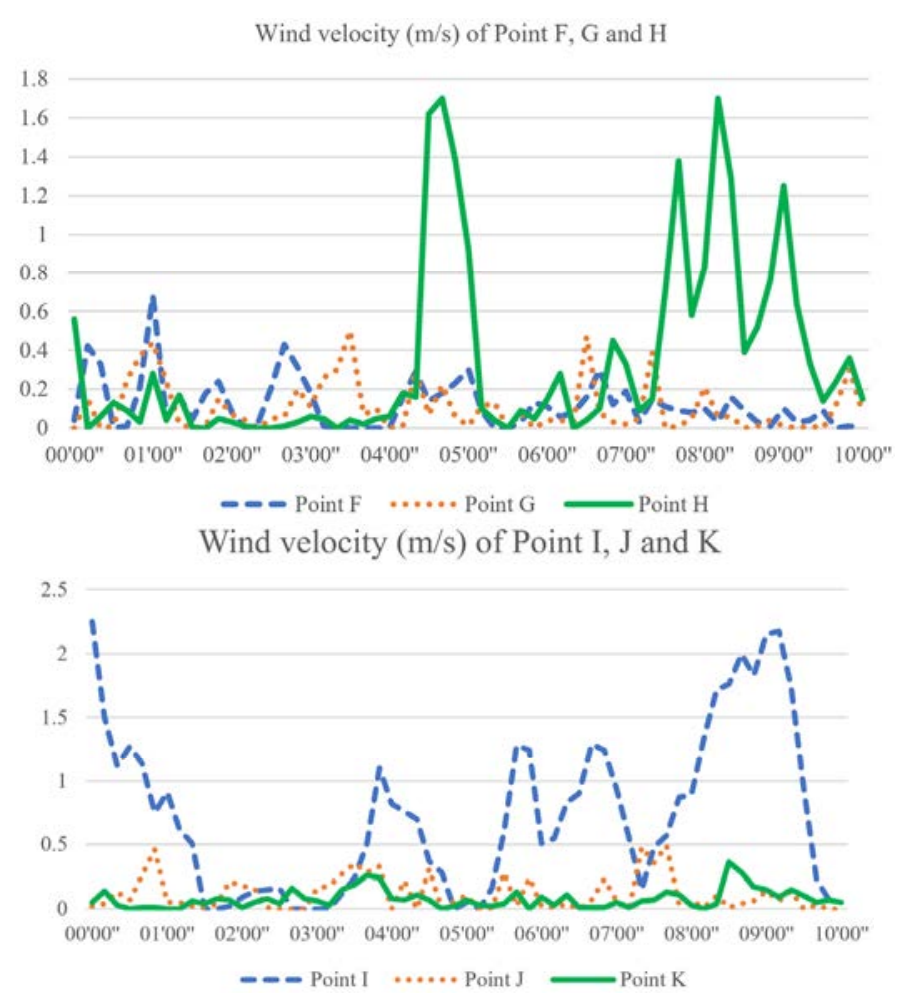

Figure 7: The locations of wind harvesting ports are designed to capture the prevailing seasonal wind. Fluctuations of wind speeds and the records of wind speeds from Point I and Point $\mathrm{H}$ are higher than those from other points.

\section{DISCUSSION}

The discussion will engage, under the notion of a passive design paradigm for large, big and tall buildings in the inner city of Shanghai and Singapore, on the possibility of passive design features, their design strategies, the combination of various green technologies, the social responsibility of architects and city fabric and patterns.

\subsection{Passive design features - natural ventilation is practicable}

The outcomes of both simulations and field measurements indicate that it is possible and feasible to apply the natural ventilation in the podiums of a compact urban area. The temperature will be out of the comfort zones indicated by the standards, but the thermal adoption, a wider range of "feel comfortable" by building occupants and their tolerance to a green building with passive design features will help to increase the acceptance of naturally ventilated environment and thermal conditions. Meanwhile, air flows strengthened by welldesigned building gaps, wind corridors, wind harvesting ports, etc. contribute to providing a pedestrian-friendly wind environment. The pilot experiment and simulation both indicates that the cost-effectively and eco-friendly passive design of natural ventilation for large, big and tall buildings in the inner city is practicable. 


\subsection{Design strategies: orientation and layout}

While the ventilation of a building would be influenced by its adjacent surroundings and the micro-climate, the urban-scale factor, regional and urban wind environment, should be paid attention to. In Shanghai and Singapore, making the most of the prevailing seasonal winds is a key strategy. The orientations of wind tunnels and wind harvesting ports should be consistent with the strong seasonal wind directions. In both selected cities, the wind tunnels or corridors generally ought to face south or north to capture more wind in the strong monsoon seasons. By doing so, natural ventilation inside the complex by prevailing winddriven design planning strategy for the mega building is possible to be archived.

The layout is another key point to make natural ventilation possible. Compared with traditional layouts of the commercial complex and campus buildings, the selected projects with passive ventilation strategies have more flexible layouts. The traditional layouts of a large volume with an air-conditioned atrium in the middle of it are commonly seen in developed and developing urban areas. This kind of design blocks the wind for its interior space and also suffocates the wind for the surrounding buildings. The new paradigm with separate volumes, smaller blocks, and wind corridors introduces the wind inside and creates a better wind environment for adjacent buildings by its permeability.

The Education Resource Center is a good example for successful passive ventilation strategy by proper orientation (North-South) and layout (interpreting the building into small volumes by inserting several wind corridors and wind harvesting ports). The challenge on this is integrating environmentally sustainable designs into this building while maintaining its architectural intent for an open-air layout. The outcome of this project is amazing since students are willing to sit in naturally ventilated spaces during self-studying. This proved that open and comfortable public areas could be achieved even amid the tropical climate of Singapore.

\subsection{Combination of various green technologies}

Some natural resources will be exhausted, and human activities have left a huge carbon footprint on this planet. Though there is a critic that engineers are doing the more significant part on green technologies to bring about higher building energy efficiency and lower environmental impact, the architects can play a crucial role as well by integrating various green strategies from the beginning of the concept stage.

The water feature and greenery in semi-open natural ventilated space not only reduce the public's reliance on air-conditioning systems but also provide entertainment and pleasure for the building occupants and passersby.
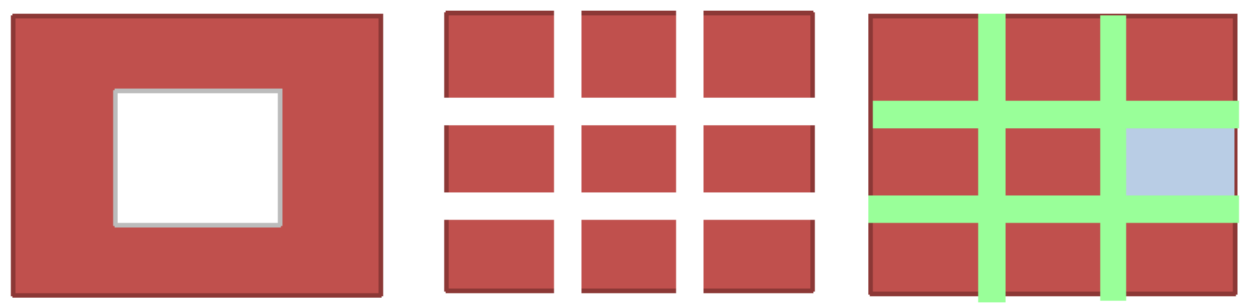

Figure 8: The flexible layout of passive design paradigm. 
When the traditional layout being turned into the new paradigm with natural ventilation, the flexible layout provides various possibilities to integrate different sustainable features.

The exemplary performance of the Education Resource Center is a naturally ventilated space for studying, and the building performs well on providing thermal comfort for its occupants and students. It indicates that capturing the wind from the North and South should be the primary objective to use natural ventilation to cool the environment in Singapore. At the same time, a major challenge addressed is making the naturally ventilated retail network comfortable for shoppers. Therefore, to archive thermal comfort, a series of passive designs constitute the system to provide a more comfortable thermal environment. A blend of passive and active designs, from the use of wind corridors and water features to vertical planting and lush landscaping, shows the possibility of a new kind of retail typology in the tropical climate.

\subsection{Social responsibility - open space and livability}

One of the social responsibilities of architects is to improve the livability of the public through their design. While designing a green building, following all the standards of green building rating systems to archive the goal of being labeled is much easier than integrating all the green concepts and technologies appropriately and efficiently. Each well-designed green building with passive strategies is an inherent showcase to raise the public's green awareness, to tell people how a building could be eco-friendly and improve the livability even in a compact urban area. A sustainable building communicates with its visitors directly with its green features. A green building should not only be tied to the checklists in green building evaluation systems but towards a more comprehensive understanding of the sustainability. In recent years green buildings are more focused on building performance and the new technologies. Engineers are sometimes taking over the architects when dealing with the green design part of the buildings. The new wave of green buildings in Asia should be sensitive to the local context, human wellness, eco-friendly sustainable development and be connected with their surroundings, even with the environmental network.

The passive design paradigm with natural ventilation is one way to achieve this. The wind tunnels can be integrated into greenery or water features, connect to the civil space inside the bigger, larger buildings. The open space design concept is extremely compatible with the passive ventilation systems.

\section{CONCLUSION, LIMITATION AND FUTURE STUDIES}

Compared to the traditional layout with air-conditioned atrium, the public space of this selected building is naturally ventilated, making the most of the prevailing seasonal wind. The general paradigm of these projects is to insert natural wind corridors among small blocks inside a building with a large volume. The results of both simulations and field measurements indicate that it is possible and feasible to apply natural ventilation within high-density urban areas to reduce the UHI effect meanwhile to ensure the thermal comfort. Meanwhile, thermal acceptance and tolerant of the public is higher when they are in the natural ventilated environment. Thus, pedestrian-friendly wind environment can be archived inside the complex by prevailing wind-driven design planning strategy for mega building, which means that the passive design paradigm for large, big and tall buildings can be one of the solutions to reducing the UHI effect in the inner city. These practical experiences are cost-effective and eco-friendly and could serve as references for other compact cities in humid and hot climate zone. 
Furthermore, the ambition of architects and green technologies are highly compatible with each other. This coexistent can benefit all relevant factors in the life cycle of a building to some extent, such as financial, cultural, social, human, architectural or reputation factors.

One limitation of this study is the lack of measured data in Shanghai. The analyses for the CITIC Plaza are based on simulated data by software due to the lack of measured data.

The research methodologies of this pilot experiment are mainly measurement and simulations. For the further study, subjective surveys, such as the questionnaires, the interviews, etc. should be conducted to analyze the human behaviors, customs, acceptances and activity patterns.

\section{ACKNOWLEDGEMENTS}

This study is supported by the NUS Research Scholarship program, Department of Architecture, School of Design and Environment, National University of Singapore. This study is also supported by the research project "Optimizing green energy-saving technology MCDM for high-rise buildings", which is the key project of the Center for Ecology and Energy-Savings for Human Inhabitation of Tongji University. Our sincere appreciation goes to Professor SONG Dexuan and his A10 research team of the College of Architecture and Urban Planning, Tongji University.

\section{REFERENCES}

[1] Oke, T.R., Boundary layer climates (2nd ed.). London: Methuen \& Co, 1987.

[2] Chow, S.D., The urban heat island of Shanghai. Acta Geographica Sinica, 37(4), 1982.

[3] Chow, S.D., The urban climate of Shanghai. Atmospheric Environment, 26(1), 1992.

[4] Nieuwolt, S., The urban micro-climate of Singapore. Journal of Tropical Geography, 22, pp. 30-37, 1966.

[5] Chow, W.T.L. \& Roth, M., Temporal dynamics of the urban heat island of Singapore, 2006.

[6] Tang, C.K., Building Energy Efficiency Technical Guideline for Passive Design. Malaysia: BSEEP, 2012.

[7] Yang, W. \& Wong, N.H., Field study of human thermal perception in urban parks in Singapore. International Journal of Sustainable Building Technology and Urban Development, 4(2), pp. 125-133, 2012. DOI: 10.1080/2093761x.2013.768184.

[8] Wong, H., Feriadi, H., Lim, P.Y., Tham, K.W., Sekhar, C. \& Cheong, K.W., Thermal comfort evaluation of naturally ventilated public housing in Singapore. Building and Environment, 37, pp. 1267-1277, 2002.

[9] Yang, F., Lau, S.S.Y., \& Qian, F., Urban design to lower summertime outdoor temperatures: An empirical study on high-rise housing in Shanghai[J]. Building and Environment, 46(3), pp. 769-785, 2010. 